\title{
Aquaculture and marine biodiversity boost: case examples from the Canary Islands
}

\author{
L. Molina Domínguez \& F. Otero Ferrer \\ Grupo de Investigación en Acuicultura (ICCM-ULPGC), Spain
}

\begin{abstract}
Biodiversity is a representation of the complexity of life in all its forms. The Convention on Biological Diversity (CBD) defines biodiversity as "the variability among living organisms from all sources, including terrestrial, marine and other aquatic ecosystems and the ecological complexes of which they are part; this includes diversity within species, between species and ecosystems".

Worldwide aquatic wild stocks and their ecosystems are in a fragile state. In the presented case example, organisms are overexploited due to its use as ornamental purposes.

Aquaculture growth in the last decade was up to $250 \%$, opposite to the stabilization of fisheries. Aquaculture had experienced a great development of culture technologies related to the increase of the world production. All these technological improvements could be applied to the reproduction and larval culture of new species with commercial interest, with a market already established. In this way, there is a growing need to promote research to develop suitable commercial scale culture protocols. The growing importance of aquaculture production should be a way to relieve this pressure on wild stocks and foster the maintenance of biodiversity whilst satisfying the growing market demand for marine species, besides the possibility of restocking of natural ecosystems in some cases highly affected.

Due to their unique biogeography, the Canary Islands display particular climate and oceanographic characteristics. These characteristics allow the presence in these islands of amphiatlantic species, mainly from the Caribbean, as well as tropical east African and Mediterranean species.

Between them, the Atlantic short-nosed seahorse Hippocampus hippocampus has been submitted to uncontrolled exploitation and inadequate management of their natural stocks. These pressures have resulted in a sharp decrease in their populations and this species is included in the Canarian Regional Catalogue of
\end{abstract}


Threatened Species. In this sense, the development of culture techniques in the last years by the Research Group in Aquaculture (GIA) has improved our knowhow and enhanced the production of juveniles from this species. At the present time, we are able to produce large quantities of juveniles. Therefore, re-stocking activities are in progress in selected sites of the Canarian coasts in order to improve the natural populations of this marine species.

In this contribution, we shall introduce the historical background and present status of aquaculture activities for re-stocking actions in the Canary Islands as a technical tool for the recovery of wild marine stocks.

Keywords: biodiversity, seahorses, Canary Islands.

\section{Introduction}

The global community recognises the importance of conserving nature as it has been recognised in international declarations, treaties, and conventions. Especially worldwide aquatic wild stocks and their ecosystems are considered globally to be in a fragile state.

A number of approaches to conservation have been suggested, focusing in ecosystems, species habitats or other area-based approaches. Although these approaches are critical to the conservation of nature, they are insufficient on their own. Just as species need well functioning ecosystems in which to live, ecosystems depend finally on their species [1]. Some species or species groups need particular attention, requiring species-focused conservation strategies especially when the public have deep attachments to particular species. These can be used to catalyze conservation efforts, being used as iconic ambassadors for the conservation of nature.

It is the particular case of the Syngnathidae family in general and seahorses' populations in particular. These animals show the uncontrolled overexploitation of marine resources and the unsuitable management of wild areas [2]. For this reason, all seahorse species have been included in Appendix II of the International Convention for Trade in Endangered Species of Wild Fauna and Flora [3]. There are more than 30 different species of seahorses spread all over the world, but only two of them are described in the Spanish coasts Hippocampus hippocampus and H. guttulatus. One of the species studied in this work, H. hippocampus, is present in the Canary Islands, and catalogued as DD (Data Deficient) by the red book of the IUCN (The World Conservation Union) and as "Vulnerable" in the Catalogue of Threatened Species of the Canary Islands (Government of the Canary Islands, D. 151/2001, 23rd July).

After two years of field study, the seahorse population in Gran Canaria Island showed a critical status [4]. The main factor threatening this species is the habitat loss and also, accidental catch or even for ornamental purposes or curiosity.

Furthermore, aquaculture had experienced a great development of culture technologies in the last decades, related to the increase of the world production. All these technologic improvements could be applied to the reproduction and larval culture of new species. Nowadays, hatcheries in most countries are capable of producing good quality seeds of marine and freshwater species, 
gradually diminishing the dependence on wild-caught seed [5], reducing the overexploitation of some species fisheries. Besides the possibility of reproduction in captivity and repopulation of natural ecosystems in some cases highly affected, is considered to be one of the solutions to promote the recovery of wild stocks.

\section{Methodology}

\subsection{Characterising species}

In the Canary Islands the presence of both European seahorse species has been referenced, $H$. guttulattus and $H$. hippocampus. However, the specific identification of these species based on morphological traits, such as the presence of skin filaments, has been frequently confused. Because of that, a molecular method has been developed for specific identification [6] based on non-invasive DNA sampling.

The sequence variation at the mitochondrial 16S ribosomal DNA (16S rDNA) marker showed fixed diagnostic differences and high average interspecific divergence $(7.1 \%)$ between these two seahorse species. Besides, the $16 \mathrm{~S}$ rDNA marker will also aid in evaluating the intraspecific diversity [7]. The results of the genetic study allowed the classification of all the seahorses sampled in Gran Canaria Island as H. hippocampus [8]. Besides, the obtained data suggest high diversity and gene flow between $H$. hippocampus populations from Gran Canaria Island, being important to prioritize their conservation.

In the Canary Islands, this species is distributed preferably in brief bottoms with vegetation, on the substratum where it is possible to find a good subjection and to pass unnoticed thanks to its great cryptic capacity.

\subsection{Developing breeding culture}

Different experiments have been carried out in order to improve the spawning quality, an appropriate handling [9] and to standardise the breeding protocol achieving more than $60 \%$ survival rate [10]. The good results obtained, especially in terms of survival, showed the adequate nutritive value of enriched Artemia metanauplii administrated in the proposed conditions. This efficient first feeding protocol with Artemia, simplifies seahorse production methods, and builds the principles for their culture to ornamental or repopulation purposes. No pathologies have been observed during the breeding period. The sexual maturity has been observed at ages of four months starting courtship behaviour.

\subsection{Tagging animals}

It is an important point to select the most suitable tags for the species used in restocking purposes. Between the existing ones on the market, the choice must be related mainly on animal size. Besides tagging system must be innocuous for the animals, allow feeding movements and possible courtships. A tag system has been tested in captivity for juveniles of this specie: VIFE - Visible Implant 
Fluorescent Elastomer (Northwest Marine Technologies, USA), applying the techniques described by Morgan and Martin-Smith, [11] and Woods and MartinSmith, [12]. The selected areas in fish body were tail and trunk using horizontal and vertical different bands number in each zone.

\subsection{Selecting zones}

The selection of concrete locations in the studied zones referred to their geographic characteristics and to their habitual use would show their potentiality for restocking purposes. The most adequate will present similar characteristics to other zones presenting natural populations of this species (bottom type, hydrodynamics, light,...). Zones presenting fishing or recreational uses (diving, boats ...) must be rejected, because the interaction could alter the results. It would be preferable to find an area geographically enclosed will make the monitoring easier. In some selected areas artificial substrate can be used to promote the permanence of liberated animals.

\subsection{Selecting animals}

The selected animals must be at least three months old; at this age their reproduction has been referred [13]. Some tests will be carried out using different sized animals, in pairs and in groups. The results of these tests will allow for evaluation of the adequate number and size of liberated animals. Besides, the liberated individuals will be genetically selected into the captivity breeding population. It is an essential step to know the intraspecific diversity of the genetic resources in the receptor population compared with selected animals for restocking purposes in order to maintain their diversity.

\subsection{Restocking assay}

Previous to liberating animals, a visual census by time unit in each selected zone will be made in order to know the previous relative abundance of this species. The restocking assay will we carried out in the selected zones using tagged animals bred in captivity in adequate size and number. The concrete moment to achieve this action will be selected taking into account especially the weather, preferably summer and autumn because of the predominant meteorology in the Canary Islands. In Canarian waters this species has shown reproduction all year around [14].

\subsection{Monitoring}

This action will be carried out at least once a week using visual census by time unit in each selected zone, locating each individual and registering different biological parameters, as substrate, behaviour, colour and reproductive state, as well as location parameters, as distance from original point, and between invidious and/or its mate.... Monitoring in selected areas provided with artificial substrate will be achieved more easily. These monitoring results will provide 
information to evaluate the main factors conditioning restocking actions in order to assess the actions to be carried out to promote a better status of the natural populations of this species in the Canary Islands. At the same time, control areas without re-stocking activities will be selected in order to evaluate the efficacy of the repopulation activities.

\subsection{Evaluating ecological and socio economical impact}

Previous to generalising these actions, it is important to evaluate the impact of restocking actions, an emphasis on wide stakeholder approaches has to be pointed out: local population, fishermen, divers,... and the public in general.

\section{Conclusions}

Biodiversity loss is the major problem in marine ecosystems sustainability. In order to sustain and increase the fish populations, a range of management approaches can be adopted. Between them, adequate re-stocking programs could be useful to improve the status of some threatened species as seahorses, but the success of these kinds of programmes is based on a detailed study on the status of the species and their habitats. Besides, important factors must be taken into consideration in order to restore the depleted populations, especially the possible genetic effects derived from using a reduced number of breeders, without this, a reduction of fitness and disease resistance may be observed. As well as the design of an appropriate tool to assess the success of the programme's effectiveness, has been also emphasized.

Nevertheless, other conservation measures, between them to remove or at least, to diminish the main factor threaten this specie, must also be taken at the same time, to assure long-term effect of restocking enhancement programs.

\section{References}

[1] IUCN Species Survival Commission (IUCN/SSC. 2008). Strategic Planning for Species Conservation: A Handbook. IUCN Species Survival Commission, pp. 11-13, 2008

[2] Vincent, A.C.J. The international trade in seahorses. TRAFFIC International, Cambridge, UK, pp.: 63-65. 1996.

[3] CITES Convention for Trade in Endangered Species of Wild Fauna and Flora, 2007 www.cites.org

[4] F. Otero, R. Herrera, L. Molina, J. Socorro, H. Fernández-Palacios \& M. Izquierdo. Estudios preliminares de las poblaciones de caballito de mar, Hippocampus hippocampus (Linnaeus, 1758), en Gran Canaria. Proc. of XV Simposio Iberico de Estudos de Bioloxia Marinha. Funchal, Madeira, Portugal, pp. 3-7, 2008.

[5] FAO. The state of world fisheries and aquaculture 2006. FAO Fisheries and Aquaculture Department. Food and Agriculture Organization of the United Nations, Roma, Italia, pp. 82-84, 2007 
[6] López, B.G. Pardo, F. Otero, P. Martínez, L. Molina \& C. Bouza. Identificación específica y análisis poblacional de caballitos de mar de las Islas Canarias. Boletín Español de Oceanografía, in press. 2007

[7] A. López, M. Vera, F. Otero, BG. Pardo, P. Martínez, L. Molina \& C. Bouza. DNA mitochondrial variation for solving species identity and population analysis of threatened seahorses from Gran Canaria Island (Spain). Journal on Fish biology, in press. 2009

[8] L. Molina, C. Bouza, A. López, B.G. Pardo, F. Otero \& P. Martínez. Species Identification and Population Analysis of Seahorses from Canary Islands (SPAIN). Proc. of Aquaculture Europe. Istambul, Turkey, pp. 48. 2007 a

[9] F. Otero Ferrer, L. Molina, J. Socorro, R. Herrera, P., M. Monroy, H. Fernández-Palacios \& M. Izquierdo, Protocolo de anestesia y recuperación para estudio de morfometría de juveniles de caballito de mar, Hippocampus hippocampus (Linnaeus, 1758) Boletín Español de Oceanografia, in press. 2007a.

[10] F. Otero Ferrer, L. Molina, J. Socorro, R. Herrera, P. Villares, M. Monroy, H. Fernández-Palacios y M. Izquierdo. Efecto de la primera alimentación en la supervivencia y el crecimiento de crías de caballito de mar, Hippocampus hippocampus (Linnaeus, 1758) Boletín Español de Oceanografia, in press. 2007b

[11] Morgan, S. \& Martin-Smith, K.. Selected Techniques for Tagging Seahorses. Project Seahorse Technical Report No.6, Version 1.0. Project Seahorse, Fisheries Centre, University of British Columbia. pp. 20, 2004

[12] Woods \& Martin-Smith, Visible implant fluorescent elastomer tagging of the big-bellied seahorse, Hippocampus abdominalis. Fisheries Research 66, pp. 363-371, 2004.

[13] L. Molina, J. Socorro, R. Herrera, F. Otero Ferrer, P. Villares, H. Fernández-Palacios \& M. Izquierdo. Experiencias preliminares de cultivo de crías de Hippocampus hippocampus (Linnaeus, 1758) en Gran Canaria. Boletín Español de Oceanografia, in press. 2007b

[14] Villares, H. P. Estudio de población del género Hippocampus en Gran Canaria: Experiencias preliminares de la viabilidad de cultivo. Thesis of International Master in Aquaculture. Universidad de Las Palmas de Gran Canaria (Spain). Pp. 87, 2005. 